\title{
Investigation of Dynamic Flight Maneuvers With an Iced Tailplane
}

Judith Foss Van Zante

Dynacs Engineering Co., Inc., Brook Park, Ohio

Thomas P. Ratvasky

Lewis Research Center, Cleveland, Ohio

Prepared for the

37th Aerospace Sciences Meeting \& Exhibit

sponsored by the American Institute of Aeronautics and Astronautics

Reno, Nevada, January 11-14, 1999

National Aeronautics and

Space Administration

Lewis Research Center

January 1999 


\section{Acknowledgments}

The authors would like to thank Richard J. Ranaudo for both his superb skills as a pilot and his keen research insights during the NASA/FAA Tailplane Icing Program. We also would like to express our appreciation to our sponsors, NASA Aviation Operations Systems and the FAA Technical Center, technical monitor, Dr. James Riley.

Trade names or manufacturers' names are used in this report for identification only. This usage does not constitute an official endorsement, either expressed or implied, by the National Aeronautics and Space Administration.

Available from

NASA Center for Aerospace Information 800 Elkridge Landing Road Linthicum Heights, MD 21090-2934

Price Code: A03
National Technical Information Service 5287 Port Royal Road Springfield, VA 22100

Price Code: A03 


\title{
INVESTIGATION OF DYNAMIC FLIGHT MANEUVERS WITH AN ICED TAILPLANE
}

\author{
Judith Foss Van Zante \\ Member, AIAA \\ Senior Engineer \\ Dynacs Engineering Co., Inc. \\ Brook Park, OH 44142 \\ Thomas P. Ratvasky \\ Research Engineer \\ NASA Lewis Research Center \\ Cleveland. $\mathrm{OH} 44135$
}

\begin{abstract}
A detailed analysis of two of the dynamic maneuvers, the pushover and elevator doublet, from the NASAFAA Tailplane Icing Program are discussed. For this series of flight tests, artificial ice shapes were attached to the leading edge of the horizontal stabilizer of the NASA Lewis Research Center icing aircraft. a DHC- 6 Twin Otter. The purpose of these tests was to learn more about ice-contaminated tailplane stall (ICTS), the known cause of 16 accidents resulting in 139 fatalities. The pushover has been employed by the FAA. JAA and Transport Canada for tailplane icing certification. This research analyzes the pushover and reports on the maneuver performance degradation due to ice shape severity and flap deflection. A repeatability analysis suggests tolerances for meeting the required targets of the maneuver. A second maneuver, the elevator doublet, is also studied.
\end{abstract}

\begin{tabular}{|c|c|}
\hline \multicolumn{2}{|r|}{$\underline{\text { Nomenclature }}$} \\
\hline alt (ft) & Altitude \\
\hline $\mathrm{C}_{\mathrm{He}}$ & Elevator Hinge Moment Coefficient \\
\hline $\mathrm{C}_{\mathrm{Lac}}$ & A/C Coefficient of Lift \\
\hline $\mathrm{C}_{\text {Ltail }}$ & Tail Section Coefficient of Lift \\
\hline $\mathrm{C}_{\mathrm{m}}$ & A/C Pitching Moment Coefficient \\
\hline $\mathrm{C}_{\mathrm{T}}$ & Thrust Coefficient \\
\hline FYE (lbs) & Yoke Force \\
\hline $\mathrm{N}_{\mathrm{z}}(\mathrm{G})$ & Vertical Acceleration \\
\hline$q(\mathrm{deg} / \mathrm{s})$ & Pitch Rate \\
\hline theta, $\theta$ (deg) & Pitch Angle \\
\hline $\mathrm{t}(\mathrm{sec})$ & time \\
\hline V.VIAS (kts) & Indicated Air Speed \\
\hline Vs (kts) & Stall Speed \\
\hline$\alpha_{\mathrm{NM}}$, alpha (deg) & $\mathrm{A} / \mathrm{C}$ angle-of-attack \\
\hline$\alpha_{1}$. TAOA (deg) & Tailplane angle-of-attack \\
\hline$\delta E$, delE (deg) & Elevator Deflection Angle \\
\hline$\delta \mathrm{F}, \operatorname{del} F(\mathrm{deg})$ & Flap Deflection Angle \\
\hline
\end{tabular}

Ice-contaminated tailplane stall (ICTS) has been identified as the cause in a number of aircraft incidents and accidents. This problem is typically manifested upon final approach, after flaps are extended. The yoke might snatch forward out of the pilot's hands and cause the nose of the aircraft to pitch down.

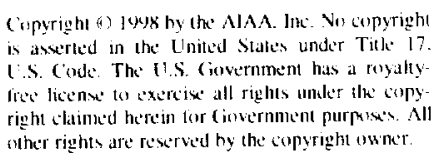

Ice contamination on the leading edge of the tail reduces both the stall angle of attack and the amount of downward lift available. For most aircraft. the center of gravity is forward of the wing center of lift. The resulting pitch down moment must be countered by the horizontal tailplane, which provides a downward or negative lift (see Figure 1). When flaps are extended, the required downward lift of the contaminated horizontal tail might exceed its diminished capacity. If the flow around the tail separates fully. the nose might pitch down suddenly.

This problem has been known for some time. Trunov and Ingleman-Sundberg ${ }^{1.2}$ conducted both wind

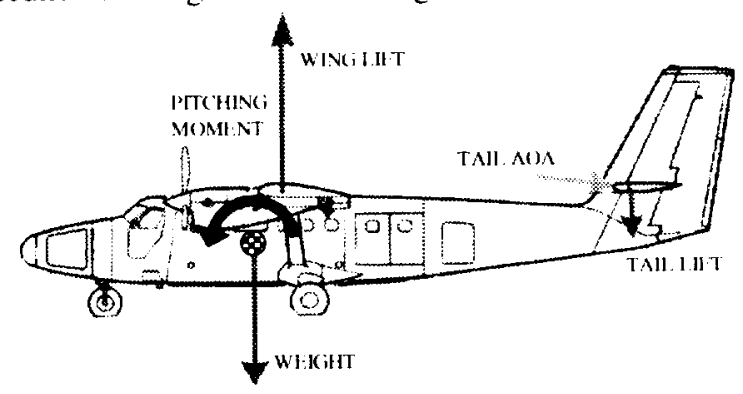

Figure 1. Schematic of aircraft with vertical component force and moment balances. Note: the contributions to the moment balance from the horizontal forces are not shown 
tunnel and flight tests on swept tailplanes with various ice shapes. They documented the aeroperformance degradation: the decrease in lift, increase in drag and increase in elevator hinge moment.

The NASA/FAA Tailplane Icing Program was constructed around these same concerns. ${ }^{3.4}$ The objectives were to (1) develop a body of knowledge and theory behind the critical degradation of the longitudinal stability and control, and (2) understand the dynamics and aerodynamics of various maneuvers that might be used for FAA certification. The final stage of this program, after icing and aerodynamic wind tunnel tests, was to conduct flight tests using the NASA Lewis Icing Research Aircraft, a modified DHC-6 Twin Otter (see Figure 1). Both steady state and dynamic maneuvers were flown with various artificial ice shapes attached to the tail. This report will focus on two of the dynamic maneuvers: the pushover and the elevator doublet.

The pushover to zero-G has been employed as a horizontal tailplane certification maneuver. Some concerns regarding this maneuver include (1) the challenge of accurate execution, (2) the necessity to design the fluid systems (e.g., hydraulics, fuel \& oil) to operate adequately in the zero-G environment, and (3) how well this maneuver assesses susceptibility to tail stall. The other maneuver. the elevator doublet, is typically flown for system identification. In addition, it was used to discriminate sensitivity to tail stall.

To test for tailplane stall, it is generally necessary to achieve the high angles of attack dynamically. The tailplane angle of attack, $\alpha_{t}$, during maneuvering, is given by (see, e.g., Etkin, p57, Eq. 3.2,12a $\mathrm{a}^{5}$ ):

$$
\alpha_{t}=\alpha_{t 0}+\Delta \alpha_{t}=\alpha_{t 0}+\Delta \alpha_{n}\left(1-\frac{\partial \varepsilon}{\partial \alpha}\right)+\frac{q l_{l}}{V},
$$

where $\alpha_{t)}$ is the trim tailplane angle of attack, $\Delta \alpha_{1}$ is the change due to the dynamic maneuver, $\Delta \alpha_{n}$ is the change in wing angle of attack, and $l$, is the distance from the CG to the tail center of lift. For the Twin Otter, the $(\partial \varepsilon / \partial \alpha)$ values vary from $0.5-0.7$. The angle of attack at the tailplane may be dynamically increased primarily by increasing the pitch rate or reducing the speed. For ease of discussion later, it is prudent to introduce some terminology. Let a pushover maneuver where the values of $\left(\alpha_{10}+\Delta \alpha_{t}\right)$ are far from $\alpha_{1}$ stull, be considered a "non-critical" pushover. Likewise, denote a case where the values of $\left(\alpha_{10}+\Delta \alpha_{1}\right)$ are close to $\alpha_{1-\text { stall }}$ as a "critical" pushover. For a target pitch rate, a noncritical pushover therefore occurs at zero flap deflection and high speed. Conversely, a critical case occurs for a full flap deflection and low speed.

This report investigates the pushover maneuver, i.e., what it is and what information it yields. It also investigates another elevator-driven maneuver, the elevator doublet. Finally, this report provides comment on the precision and accuracy of one pilot's ability to achieve the target parameters of the pushover.

\section{Flight Card}

\section{Experimental Procedure}

Using the DHC-6, research flights were conducted with artificial ice attached to the leading edge of the horizontal tailplane. In addition to a clean leading edge baseline ( $\mathrm{Ba}$ ) case, three ice shapes, depicted in Figure 2 , were flown. Two of these shapes were grown in the NASA Lewis Icing Research Tunnel using FAR 25 , Appendix $\mathrm{C}$ conditions. In increasing order of severity, these included an inter-cycle residual ice (RI) and a failed boot (FB) ice shape. The third and most critical shape, as determined by wind tunnel tests conducted at The Ohio State University's 7'x 10' wind tunnel, was a $2-\mathrm{D}$ shape used in previous stability and control flight tests (S\&C). Additional primary parameters for each of the steady state and dynamic maneuvers were flap deflection, thrust setting and airspeed. The flaps were deflected $0^{\circ}, 10^{\circ}, 20^{\circ}, 30^{\circ} \& 40^{\circ}$. The power was set for cruise, $C_{T}=0.1$. Three or four speeds were selected from the range $V_{s}$ to $1.6 \mathrm{Vs}$. In all, this program generated 2000 test points and 14 gigabytes of data.

\section{Data Acquisition}

The on-board data system recorded 95 channels of data at $100 \mathrm{~Hz}$. Included were inertial data (accelerations and angular rates), air data (aircraft angles, speed, temperature, altitude), control surface deflections and corresponding pilot forces, engine parameters, and 62 pressure measurements at the tailplane. These included three five-hole probes located along the span, and a

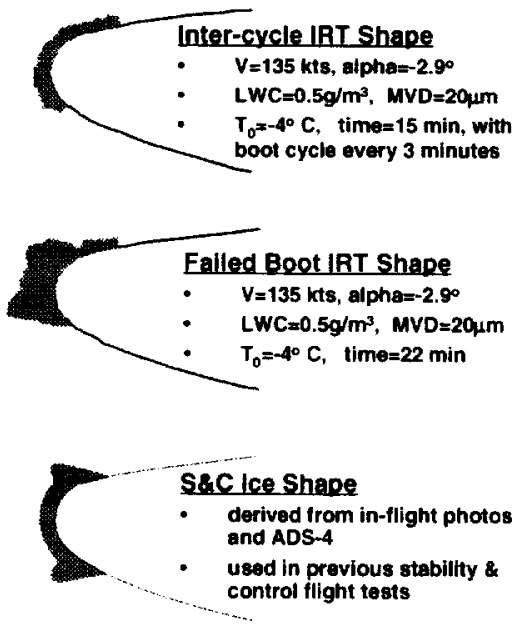

Figure 2. Schematic of ice shapes tested on the Twin Otter horizontal stabilizer. 
belt to measure the static pressure distribution along the chord. Three video cameras were also employed: one to monitor the pilot actions and reactions, one to record the horizon, and one to observe tufts placed on the underside (suction surface) of the tailplane.

\section{Maneuver Description}

The Pushover

The pushover maneuver was similar to those described in current aircraft certification programs. ${ }^{6}$ It required that the pilot (1) hit a specified vertical acceleration, $N_{\text {: }}$. (or pitch rate, $q$ ) at (2) a target velocity, $V$, and (3) as the nose of the aircraft tracked through the horizon. To achieve these targets, the aircraft flew in a parabolic trajectory similar to those that simulate micro-gravity. The following description of the maneuver can also be seen in the time histories presented in Figure 3. To start, the aircraft was configured by fixing the flap deflection and thrust, then trimmed in straight and level flight at the target speed. The corresponding pitch angle, $\theta$, was noted. Before initiating the maneuver, the pilot must first dive to build speed, and then pull up to bleed speed and increase the pitch attitude prior to pushover. To enter the maneuver itself (maximum $N_{z}$ at $t=16,31$ \& $42 \mathrm{~s}$ ). the pilot pushed forward on the yoke (step increase in $\delta E$, decrease in $F Y E$ ) five to ten knots above the target speed. With this push came a rapid decrease in $N_{\text {s }}$ from 2-0G. Note the velocity continued to decrease for some time. With the elevator fixed forward. the pilot attempted to hit the $N_{*}, V$ and $\theta$ targets. After the targets were achieved, or when the flap extension speed, $\mathrm{V}_{\mathrm{FE}}$. was approached, the yoke was pulled back.

The pass/fail criterion for this maneuver concerns whether or not a control force reversal (CFR) is experienced. This would most likely occur while $\delta E$ is fixed at its constant maximum. Note that there are two inputs to the force measured at the yoke: (1) the pilot input and (2) the pressure field around the elevator. Should the control force change (lighten) while the elevator position is held constant, the change must be due solely to a changing pressure field, e.g.. flow separation.

For this program, each test point contained three parabolas for three pushovers. For the Twin Otter, these parabolas typically lasted up to 20 seconds with a maximum of five seconds in micro-gravity. The pushover was flown for all ice shapes, flap deflections and airspeeds. For the Failed Boot and S\&C ice shapes, however, the flap deflection was limited to $\delta F=20^{\circ}$ because CFRs were experienced at the lower speeds.

The data presented in Figure 3 are a limited set of the time histories for one of the non-critical pushover test points: Residual Ice shape with $\delta F=0^{\circ}$. The targets were $N_{-}=0 \mathrm{G}, V=100 \mathrm{kts}=1.5 \mathrm{Vs}$ and $\theta=4^{\circ}$. The third pushover $(t=49 \mathrm{~s})$ came closest to the targets. For all

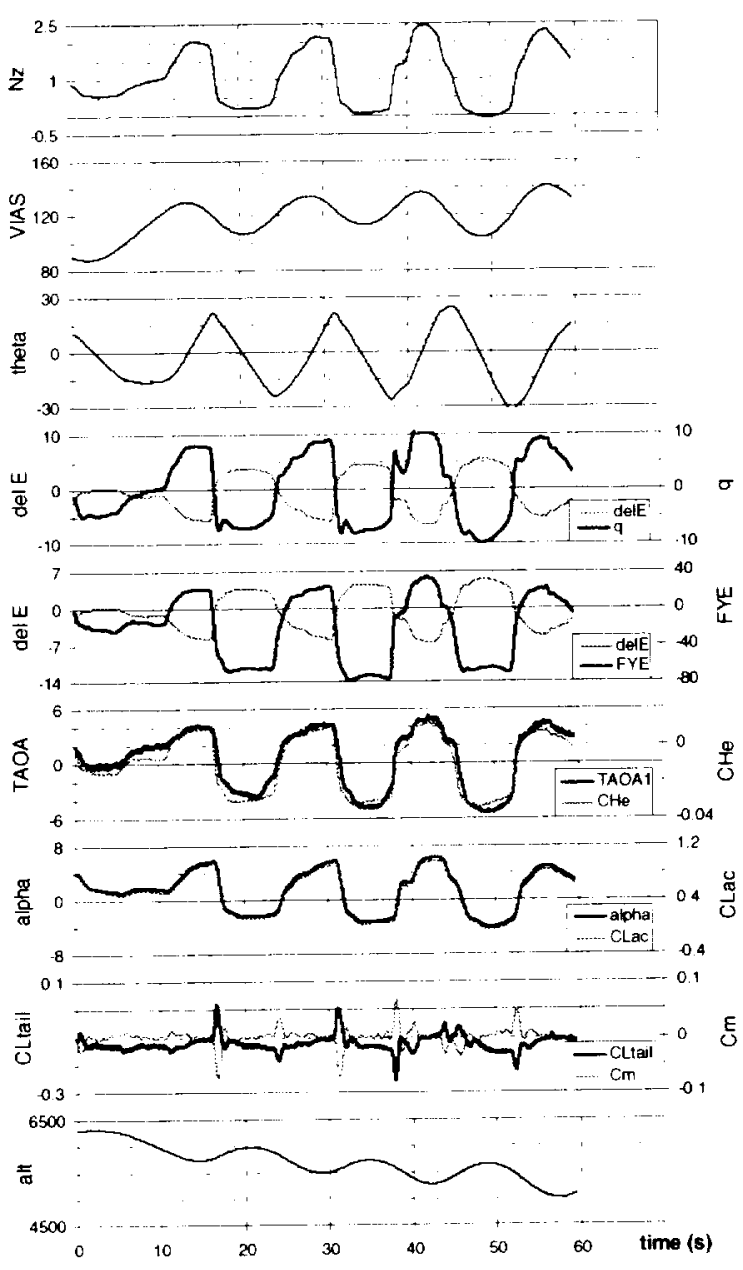

Figure 3. Non-critical pushover time histories: Residual Ice, $\delta F=0^{\circ}, V=100 \mathrm{kts}=1.5 \mathrm{Vs}$.

three pushovers during this test point the pilot over flew the speed. However, he did track through the horizon $(\theta$ $=3^{\circ}$ ) at the minimum $q$ or $N_{*}$. Note how closely the pitch rate mimics the vertical acceleration. This configuration easily passed the certification control force criterion: while the elevator was trailing edge down (TED; $\left.\delta E>0^{\circ}\right)$, the push force $(F Y E<0)$ remained fairly flat. The most negative $\alpha$, was $-5.4^{\circ}$. compared to the steady IG flight value of $0^{\circ}$. Moreover, for this noncritical case, the $\alpha_{1}$ and $C_{H}$ traces are highly correlated $(r=0.98)$. This suggests that as the yoke was pushed forward ( $C_{H^{\prime}}$ decreased) the angle of attack at the tailplane also decreased with the nose down command. Likewise, when the pilot pulled the yoke back. $\alpha_{1}$ was again able to match. The high degree of correlation between the aircraft angle of attack and lift coefficient indicates that the maneuver took place entirely within the linear region. As expected, the $C_{\text {ltuil }}$ value was essentially constant with the exception of a transient response to the elevator deflection. and oppositely correlated to $C_{m}$. 


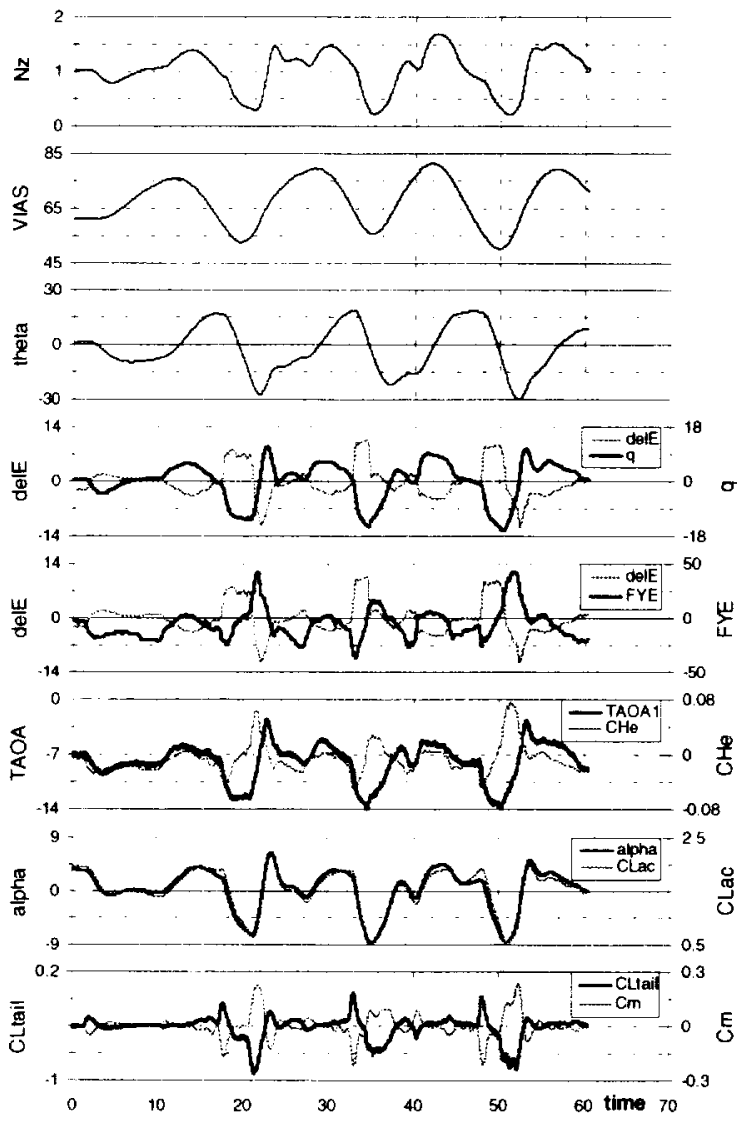

Figure 4. Critical pushover time histories: Failed Boot, $\delta F=20^{\circ}, V=55 \mathrm{kts}=1.0 \mathrm{Vs}$.

For comparison, a set of critical case time histories is presented in Figure 4. These plots are for the Failed Boot at $\delta F=20^{\circ}, V=55 \mathrm{kts}=1.0 \mathrm{Vs}$. Because of the flap setting and low speed, the minimum $N_{z}$ was $0.2 \mathrm{G}$; the target $\theta$ was $-1.8^{\circ}$ (as determined from the steady state trim test point). The second pushover $(t=35 \mathrm{~s})$ came the closest to the target values. It is interesting to note that whether or not the control force for this pushover reversed is not as easy to determine as for the other two, which were achieved at slightly lower speeds. Without instrumentation, it would be up to the pilot to make the determination. "Also note the lack of correlation $(r=-0.03)$ between $\alpha_{1}$ and $C_{H_{e}}$ for this critical pushover. When the yoke was pushed forward $(t=$ $17,32 \& 47 \mathrm{~s}$ ), they started out together but diverged with the control force lightening. It seems that the correlation between $\alpha_{1}$ and $C_{H e}$, or lack thereof, could also indicate an impending tail stall condition. However, since these involve higher level measurements $\left(\alpha_{1}\right)$ and calculations $\left(C_{H e}\right.$ from $\left.F Y E\right)$, further examination of

\footnotetext{
- The control force did cross the neutral axis 0.10 s before the elevator returned TEU. At $t=0 \mathrm{~s}$, however. $F Y E=-1.8 \mathrm{lbs}$; this reference point was crossed $0.13 \mathrm{~s}$ before the elevator returned TEU.
}

this effect was not pursued. As with the non-critical pushover, $\alpha$ and $C_{\text {Lac }}$ are still highly correlated. The curves do depart, however, and the biggest departures occurred when the elevator was deflected TED. At $\delta F=$ $20^{\circ}$, both $\alpha_{1}$ and $C_{L x a i l}$ became more negative. The variations in $C_{m}$ nearly doubled from the $\delta F=0^{\circ}$ case.

\section{The Elevator Doublet}

The elevator doublet consisted of four step inputs to the elevator initiated from straight and level flight. Each input was intended to excite the longitudinal short period response. This maneuver demonstrates the effect of tailplane ice on the dynamic longitudinal stability and control, and is typically associated with parameter estimation studies.

The aircraft was trimmed for the target flap deflection, speed and power. As illustrated in Figure 5, one series of negative and positive deflections were made. and immediately followed by a second series.

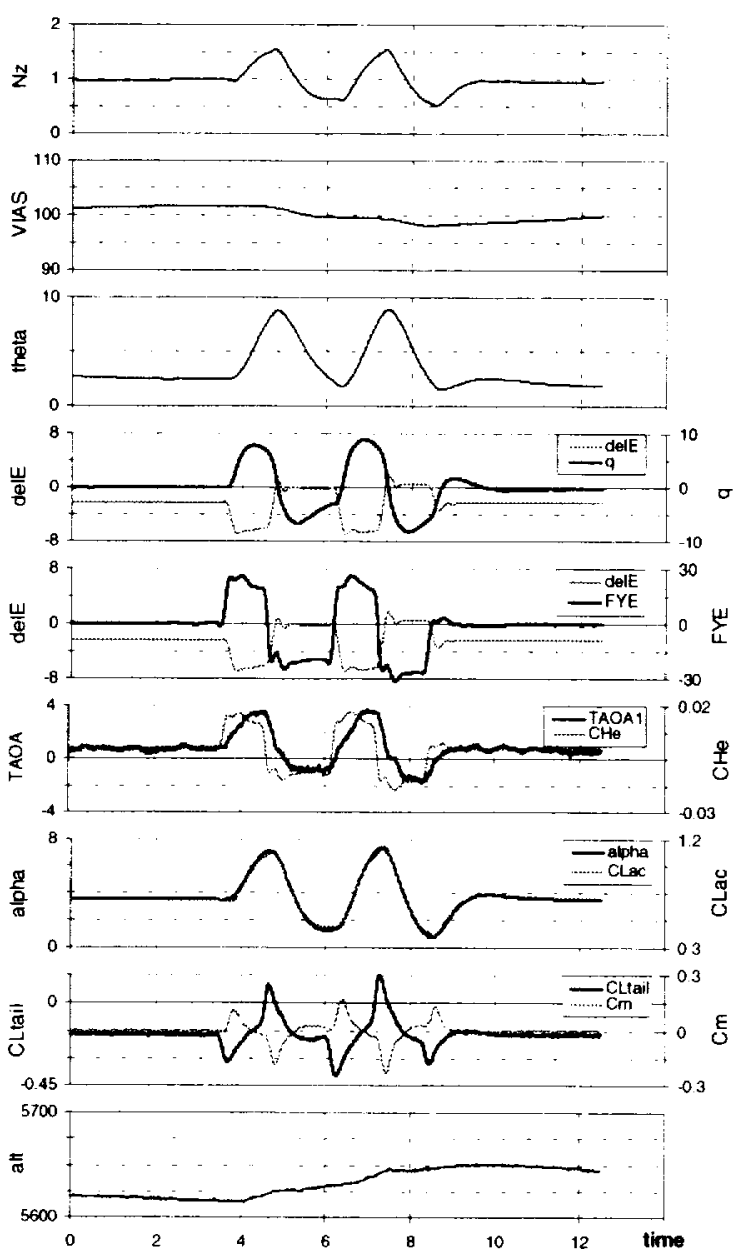

Figure 5. Non-critical elevator doublet time histories: Baseline, $\delta F=0^{\circ}, V=100 \mathrm{kts}=1.5 \mathrm{Vs}$. 
All ice shapes, flap deflections, and speeds were flown. For the Failed Boot and S\&C ice shapes, however, the flap deflection was limited to $\delta F=30^{\circ}$ because the pitch response was highly (dangerously) undamped, and CFRs were experienced. Recall the corresponding pushovers were limited to $\delta F=20^{\circ}$.

An elevator doublet for the Baseline case, $\delta F=0^{\circ}$, $V=100 \mathrm{kts}=1.5 \mathrm{Vs}$ is presented in Figure 5. The elevator is pulled trailing edge up (TEU, $\delta E$ decreased) at $t$ $=3.8 \& 6.1 \mathrm{~s}$ and pushed TED at $4.4 \& 7.2 \mathrm{~s}$. For each elevator deflection, the control force, $F Y E$. remained flat. The pitch rate response. $q$, peaked while the elevator was held at an extrema, then started to recover (diminish) before the elevator was moved. Note that in

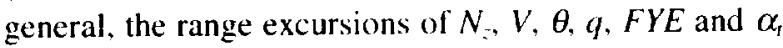
are much smaller for the elevator doublet than the pushover. The one exception to this is the $C_{m}$ values; the elevator input is typically sharper than for the pushover, therefore, the response is correspondingly sharper. The sharper elevator input is also the suspected cause for the lessened correlation between $\alpha_{t}$ and $C_{H e}$. The tailplane response, $\alpha_{l}$, lags behind the $C_{H e} / F Y E$ input.

For comparison, an elevator doublet with the Failed Boot ice shape at $\delta F=20^{\circ}$ and $V=1.0 \mathrm{Vs}$ is presented in Figure 6 . Note this is the same aircraft con-

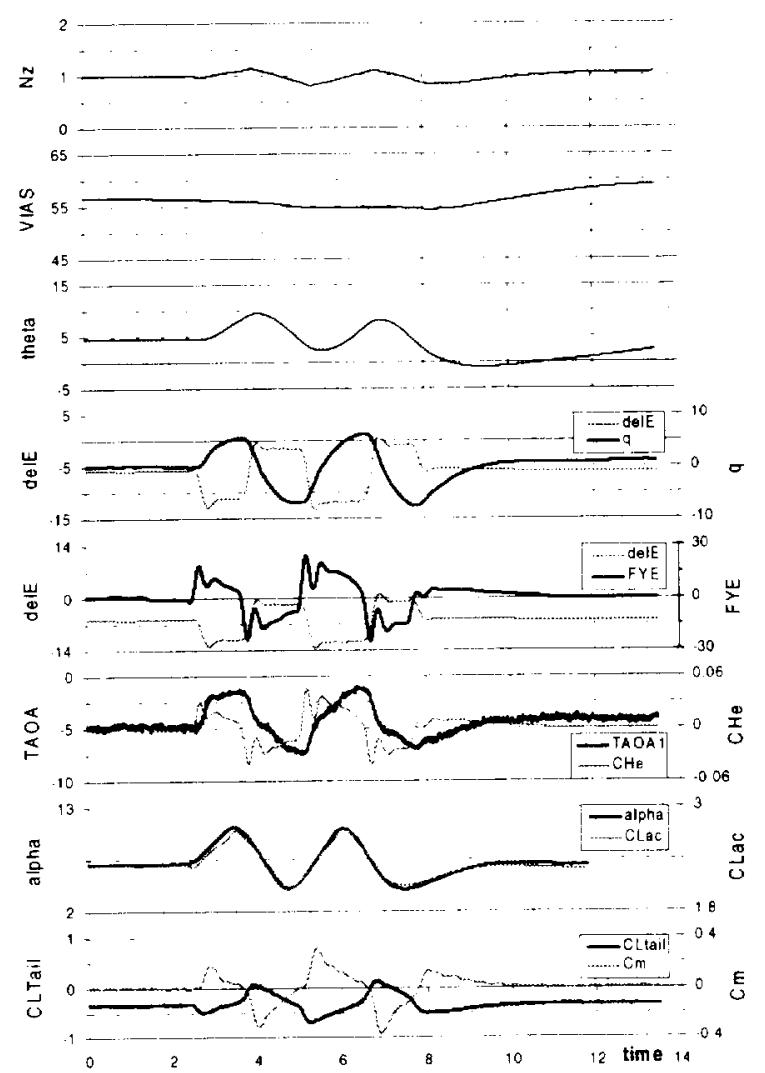

Figure 6. Elevator Doublet time histories for same configuration and flight conditions as in Figure 4: Failed Boot, $\delta F=20^{\circ}$ and $V=55 \mathrm{kts}=1.0 \mathrm{Vs}$. figuration and flight condition as that in Figure 4. Of particular interest are the control force and pitch rate responses. The FYE lightens and $q$ is undamped for each of the four elevator deflections. The minimum $\alpha_{t}$ for the elevator doublet is about half that of the corresponding pushover. Again, the ranges of all variables. except $C_{m}$. are a fraction of those for the pushover.

\section{Two Paths to Stall}

In this section, the effects of increasing ice contamination and increasing flap deflection are analyzed. Analyses include time history co-plots of $\delta E \& F Y E$, which relate directly to the certification criterion for the pushover, and $\delta E \& q$. which is an important and relevant comparison for the elevator doublet. Moreover. crossplots of $N_{-}$vs. FYE and $\delta E$ vs. $q$ highlight the response of the tailplane to a given input.

\section{Effect of Ice Shape Severity}

Co-plots of $\delta E \& F Y E$ for a pushover maneuver with each of the four leading edge contamination cases appear in Figure 7. The pushovers at $\delta F=20^{\circ}$ achieved the same targets: $N_{z}=0.2 \mathrm{G}$ (minimum possible) and $V$ $=50 \mathrm{kts}=\mathrm{Vs}$ (except the Residual Ice case. where $V=$ $57 \mathrm{kts}$ ), and represent the most critical case for the Failed Boot and S\&C ice shapes. Here, the pushover was defined to run from maximum $N$ : to maximum $N_{\text {. }}$. The circles in Figure 7 mark the elevator return TEU, i.e. the point when the elevator moved in the TEU direction: they will be referenced again in Figure 11. One can see (also from Figure 3) that this time period generally starts prior to the elevator deflecting TED, and includes the elevator returning TEU. Of interest is the response of the control force with increasing ice shape severity. For the Baseline case, FYE is essentially flat. For the Residual Ice shape, FYE lightens substantially before the elevator is relurned. The $F Y E$ actually crosses the neutral point for both the Failed Boot and S\&C ice shapes; i.e., a CFR was experienced. The oscillations in both the $\delta E$ and $F Y E$ profiles for the $S \& C$ shape indicate the difficulty the pilot had holding the elevator steady. The video that recorded the tufts on the tailplane indicates that this was due 10 unsteady separation and reattachment over the clevator.

Figure 8 depicts the corresponding $\delta E \& q$ plots for comparison. With the Baseline and Residual Ice configurations, the pitch response was damped: $q$ peaks near the middle of the elevator TED portion. For the Failed Boot and S\&C ice shapes, on the other hand, the pitch response was undamped: $q$ only ceased to increase after the elevator was returned TEU. In fact. for the scores of maneuvers examined this trend held true. In the Twin Otter, if the control force reversed, the pitch rate response was also undamped. 


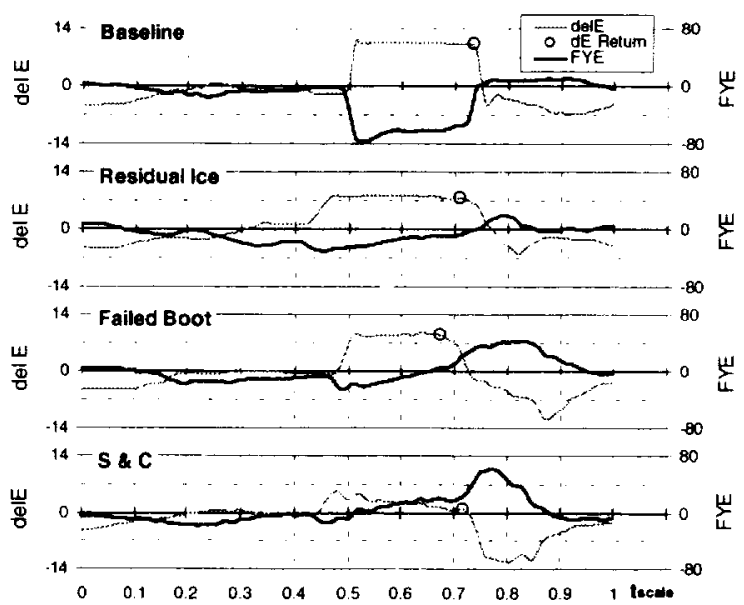

Figure 7. Effect of increasing ice contamination severity on the control force reversal criterion. Pushovers at $\delta F=20^{\circ} . N_{z}=0.2 \mathrm{G}, V=50 \mathrm{kts}=\mathrm{Vs}$.

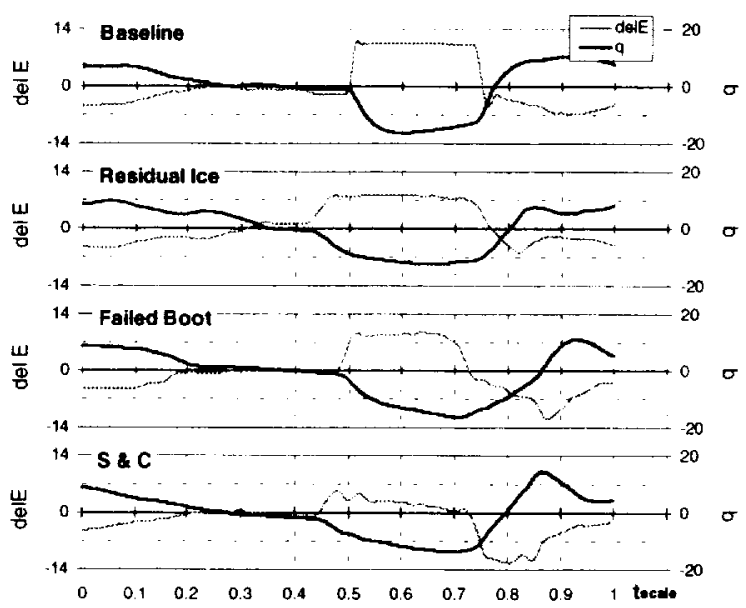

Figure 8. Effect if increasing ice contamination severity on pitch rate response criterion. Same pushover data as in Figure 7.

The elevator doublets allowed flight to even more extreme configurations than the pushovers. The full time histories in Figures 9 and 10 show control force and pitch damping co-plots for $\delta F=30^{\circ}$ and $V=85 \mathrm{kts}$ $=1.6 \mathrm{Vs}$ with the various ice shapes. The progression from control force lightening to reversal and the degradation in the pitch rate response are well illustrated in these plots. The starting elevator position $(t=0)$ indicates the loss of elevator authority with increasing ice severity: for the Baseline case, $\delta E_{0}=6.7^{\circ}$, for $S \& C$, $\delta E_{i)}=-1.3^{\circ}$.

A performance plot presented in REF. 1 is $N$. vs. $F Y E$. The data presented in Figure 11 a is the portion of the pushovers presented in Figures 7 and 8 that began (near IG flight) with the elevator deflecting TED and ended at the minimum $N_{*}$. Recall from Figure 7 that the circles, mark when the elevator was returned TEU. For

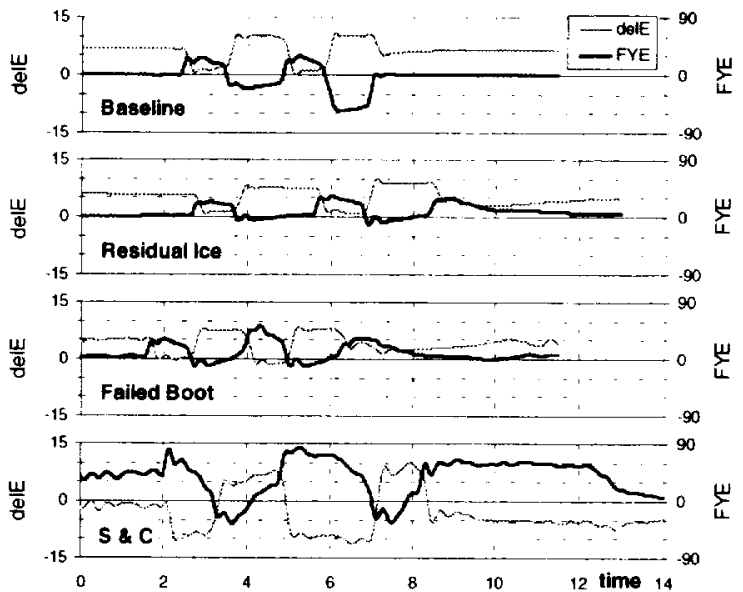

Figure 9. Effect of increasing ice contamination severity on the control force reversal criterion. Elevator doublets at $\delta F=30^{\circ}, V=85 \mathrm{kts}=1.6 \mathrm{Vs}$.

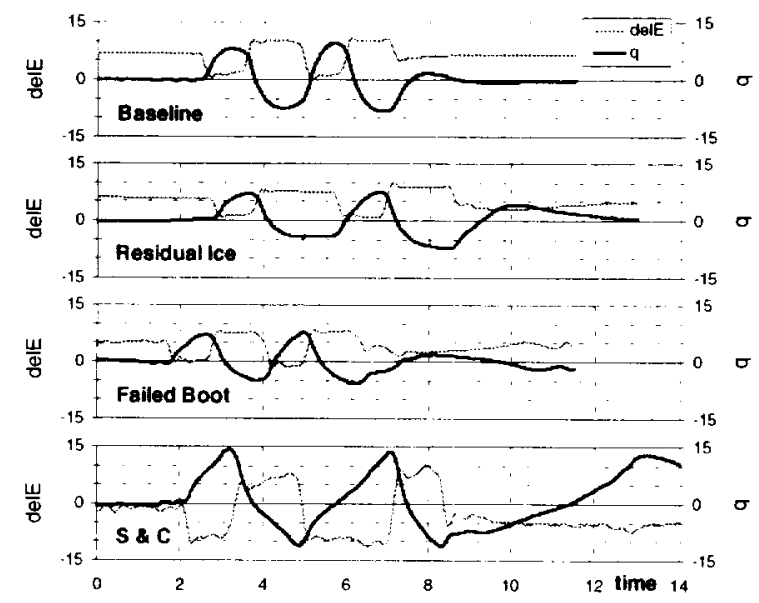

Figure 10. Effect of increasing ice contamination severity on the pitch rate response criterion. Same elevator doublet data as in Figure 9.

the Baseline case, the force remained a push throughout the flight to minimum $N_{5}$, including the elevator's return TEU. The degradation with increasing ice shape severity culminates with the $\mathrm{S} \& \mathrm{C}$ line. The control force reversed before the plane went to $0.6 \mathrm{G}$.

In Figure $1 \mathrm{lb}$, the same data sequence is crossplotted with $\delta E$ vs. $q$. Again, the elevator push starts near $q=0$, and causes $q$ to increase negatively. The more interesting dynamics appear in the lower-right quadrant. For the Baseline case, the short period response is clear: while the elevator was fixed TED, the pitch response peaked then subsided before the elevator was restored TEU. For the Failed Boot case, on the other hand, even after the elevator returned TEU more than $10^{\circ}$, the aircraft continued to pitch over at the near constant rate of $-16 \mathrm{deg} / \mathrm{s}$. 

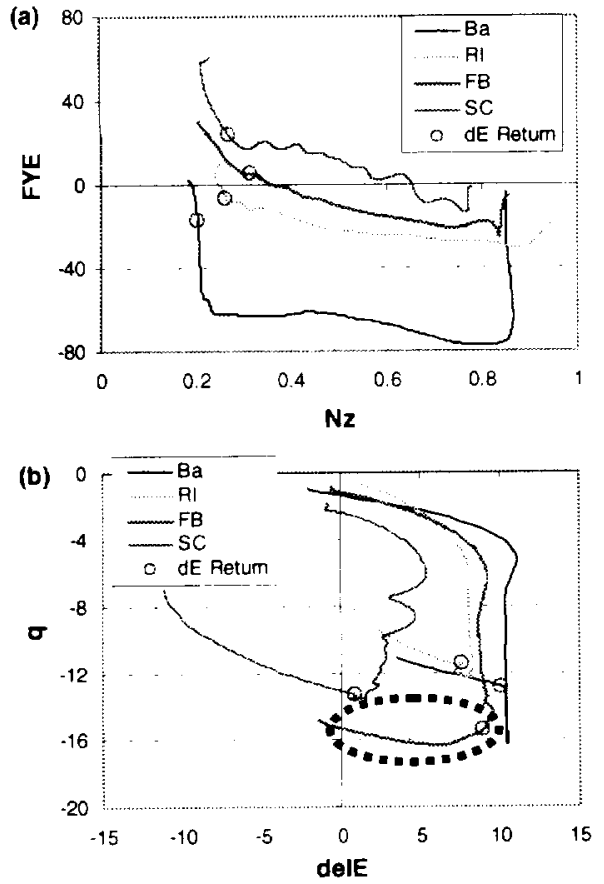

Figure 11. Performance plots for the pushover with increasing ice contamination severity. Same data source as in Figures 7 and 8: $\delta F=20^{\circ}, V=50 \mathrm{kts}=1 \mathrm{Vs}$ : (a) $F Y E$ vs. $N$. (b) $q$ vs. $\delta E$.

\section{Effect of Flap Deflection}

In addition to adding ice, another known path to tail stall ${ }^{1,3}$ is increasing flap deflection. For a given ice contamination, the Failed Boot shape, pushovers were performed for $\delta F=0^{\circ}, 10^{\circ}$ and $20^{\circ}$. Their time histories are shown in Figure 12. The achieved targets were $N_{:}=$ $0 G$ and $V=1.15 \mathrm{Vs}$. It is clear that for $\delta F=0^{\circ}$, the control force remained flat during the elevator TED portion. For $\delta F=10^{\circ}, F Y E$ lightened, almost to reversal. For $\delta F=20^{\circ}$, CFRs occurred for all three pushovers. In fact, the pilot applied a control force in excess of 100 Ibs to restore the elevator. Figure 13 shows the corresponding pitch rate responses. As expected for $\delta F=0^{\circ}$, the $q$ trace indicates that the short period was excited with the elevator push. For $\delta F=10^{\circ}$. the peak $q$ still occurred while the elevator was held TED. For $\delta F=$ $20^{\circ}$, however, the pitch response was clearly undamped.

Similar plots were made in Figure 14 for the elevator doublet with the Failed Boot ice shape and flap deflections from $\delta F=0^{\circ}$ to $30^{\circ}$. The speed was $V=1.5 \mathrm{Vs}$. In addition to noting the loss of elevator authority, Figure 14 also demonstrates the stick lightening in the forward direction. For nominally the same $\Delta \delta E=-6^{\circ}$ deflection TEU near $t=1.6 \mathrm{~s}$, the required pull force was a nominally constant $30 \mathrm{lbs}$ for all flap deflections. On the

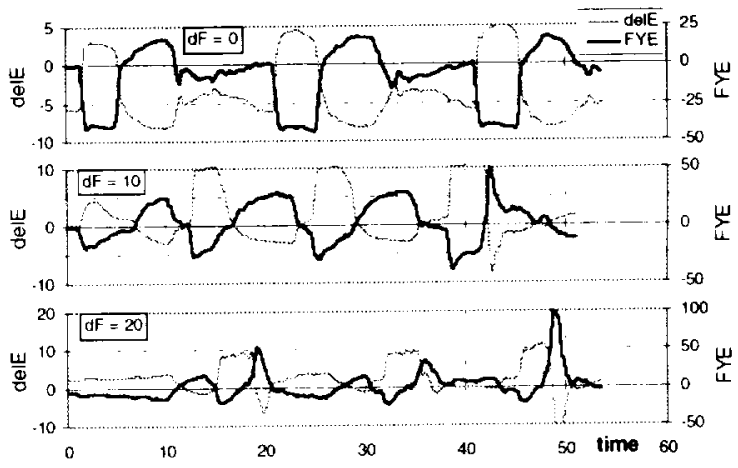

Figure 12. Effect of flap deflection on control force criterion. Failed Boot shape, $N_{2}=0 \mathrm{G}, V=1.15 \mathrm{Vs}$.

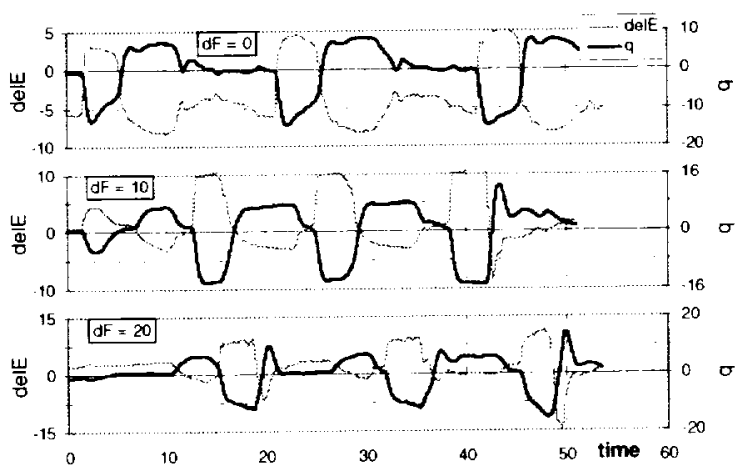

Figure 13. Effect of flap deflection on pitch response criterion. Same data source as in Figure 12.

other side, for the nominally constant $\Delta \delta E=+9^{\circ} \mathrm{de}-$ flection TED near $t=2.8 \mathrm{~s}$, the required control force lightened considerably. For $\delta F=0^{\circ}$, the push force was $-35 \mathrm{lbs}$. For $\delta F=30^{\circ}$, on the other hand, the pilot only applied -11 lbs push force to move the elevator the same distance. Moreover, immediately after that, the control force continued to lighten and cven reversed.

The pitch rate responses to increasing flap deflection with a contaminated tailplane are shown in Figure 15. Observe how $q$ transitions from all four damped responses at $\delta F=0^{\circ}$, to all undamped responses at $\delta F=30^{\circ}$. 


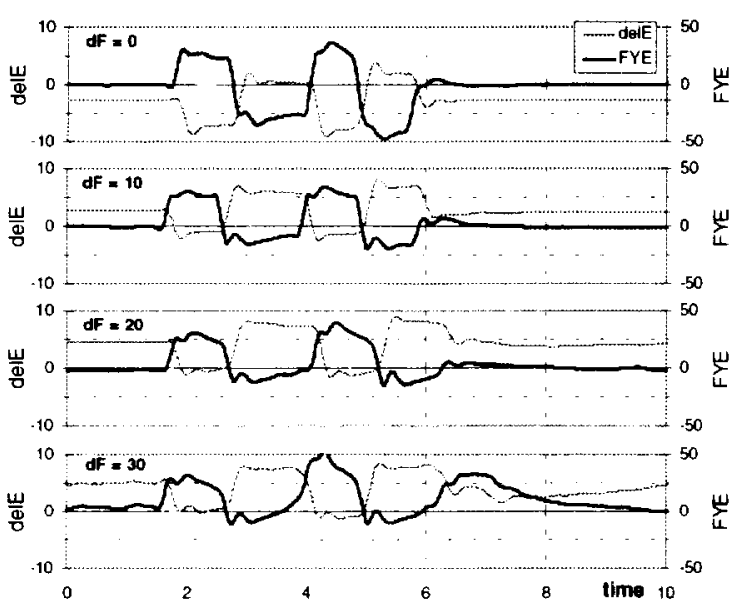

Figure 14. Effect of flap deflection on elevator doublets with Failed Boot ice shape and $V=1.5 \mathrm{Vs}$ : Control force criterion.

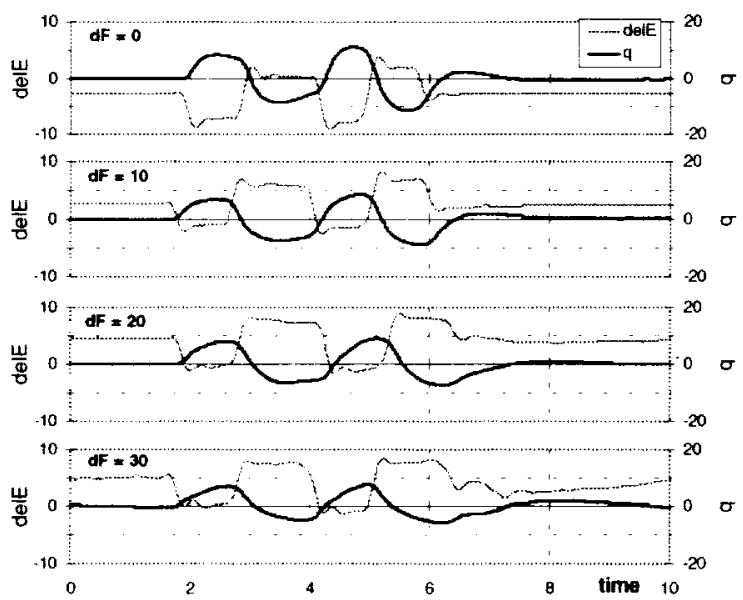

Figure 15. Effect of flap deflection on elevator doublets with Failed Boot ice shape and $V=1.5 \mathrm{Vs}$ : pitch rate response.

\section{Repeatability Analysis}

One of the key questions regarding the pushover is how precisely it must he flown. If, for example, a test point for the pushover is flown three knots below the lowest target speed and a control force reversal is experienced, should the aircraft be certified if it would have passed at the target speed? What if the point is flown three knots too fast? In general, what magnitude of error is tolerable, and what is not? The research conducted for the NASA/FAA Tailplane Icing Program can report on, and only on, how closely one pilot was able to achieve the target conditions in the modified DHC- 6 test aircraft.

The nature in which these pushovers were flown three pushovers to the same targets per test point allow for such a repeatability analysis. With these flight tests, an error analysis may now be made. Presented herein is a detailed description of the analysis and results from both a non-critical and critical configuration.
Description of the Repeatability Analysis

One way to accomplish a repeatability study is a point by point comparison between the three maneuvers. That is, to superimpose all three maneuvers on a common time axis. The time index for each maneuver would be scaled to run from zero to unity, $t_{\text {scate }} \in[0,1]$ (see Figure 16). To achieve this, the first task was to precisely define a "maneuver". A choice was made that the vertical acceleration $N_{z}$ would be the governing factor." A maneuver was defined to begin and end with the pullup, i.e., from maximum $N_{z}$ to maximum $N_{*}$. It also became apparent that the time of the minimum $N_{z}$ location needed to be specified. Otherwise, it might appear anywhere from 50 to $80 \%$ of the total maneuver time. The optimal place to fix $N_{--\min }$ is the average location of the maneuvers under consideration. For this example, it was set to $50 \%$. The procedure to define the time axis is:

1) Find the actual times of the two $N_{i-m a 1 .}, t_{0} \& t_{t}, t_{0}$ determine the period $T$.

2) Find the actual time of $N_{--m i n}$.

3) To fix the scaled time of $N_{--m i n}$ at 0.5 , subtract $0.5 T$ from the actual $N_{--\min }$ time to find the new start time. Add the total period to the start time to find the new end time.

4) With the new bounds of the maneuver determined, the scaled time becomes $t_{s c u t e}=\left(t-t_{0}\right) /\left(t_{1}-t_{0}\right)$.

Such a collapse of the $N_{*}, V$ and $\theta$ target data is presented for both a non-critical and a critical pushover. Figure 16 depicts the same non-critical configuration presented in Figure 3: Residual Ice, $\delta F=0^{\circ}, V=1.5 \mathrm{Vs}$. The thin lines represent the scaled version of the data presented at the times indicated (e.g., $14-28$ seconds). Figure 17 depicts the Failed Boot, $\delta F=20^{\circ}, V=1.0 \mathrm{Vs}$ case. The corresponding data appears in Figure 4 from 4.3 - 55 seconds and in Figure 7.

Once the traces are synced and scaled, statistical analyses may now be performed. To make the task of directly comparing all three scaled time traces more manageable, the time axis was subdivided into equaltime 'bins'. For this exercise, the number of maneuvers $N_{\text {man }}=3$, the number of bins $N_{\text {bin }}=20$ which left about $N_{s i}=70$ data points per bin. Let the term $Q(i, j, k)$ identify the $i^{\text {th }}$ point of the $j^{\text {th }}$ maneuver in the $k^{\text {th }}$ bin for a quantity $Q$. The first step is to average each maneuver within a bin.

$$
\bar{Q}(j, k)=\frac{1}{N_{s i z}} \sum_{i=1}^{N_{d i j}} Q(i, j, k)
$$

\footnotetext{
" This choice of an output parameter was based on the fact that the criteria for the pushover maneuver is written to this parameter, and that it has obvious demarcations between maneuvers. Another choice might have been the input parameter, elevator deflection. However. this choice was not "clean" in that the elevator moved differently for different configurations: more decisions would have to be made.
} 


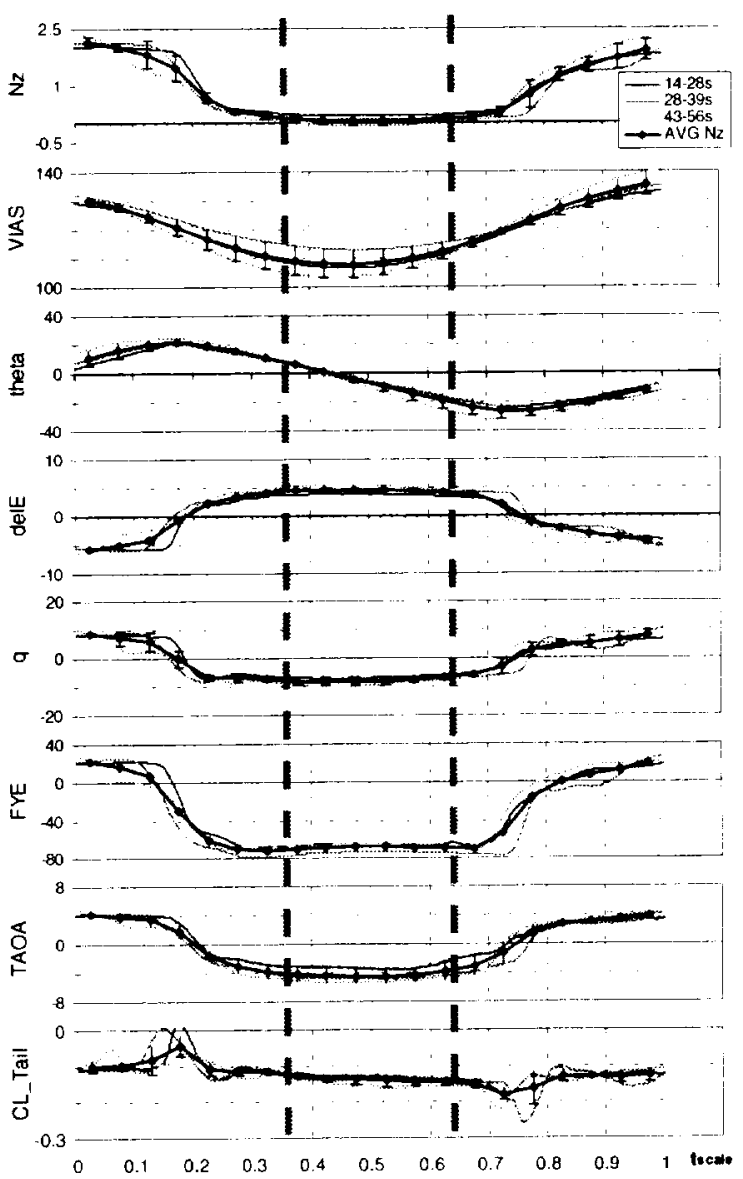

Figure 16. Three maneuvers (thin lines) and their average (thick line) vs. scaled time for Residual Ice, $\delta F=0^{\circ}$, $V=100 \mathrm{kts}=1.5 \mathrm{Vs}$ test point. Error bars and $\bar{s}_{t u}$ averaging region are indicated.

Next, those average values for each maneuver are averaged within the bin, creating a bin average, $\overline{\bar{Q}}(k)$.

$$
\overline{\bar{Q}}(k)=\frac{1}{N_{\operatorname{man}}} \sum_{j=1}^{N_{\operatorname{man}}} \bar{Q}(j, k)
$$

In the figures, the bin average for each quantity is represented with the thick line. The standard deviation of each bin, $s(k)$, comes from the three differences between each trace average and the overall average.

$$
s(k)=\left[\frac{\sum_{i=1}^{N m(m)}(\bar{Q}(j, k)-\overline{\bar{Q}}(k))^{2}}{N_{m m}-1}\right]^{1 / 2}
$$

The final error, $\bar{s}$, is the average of all of the bins.

$$
\bar{s}=\frac{1}{N_{\text {hin }}} \sum_{k=1}^{N_{\text {hin }}} s(k)
$$

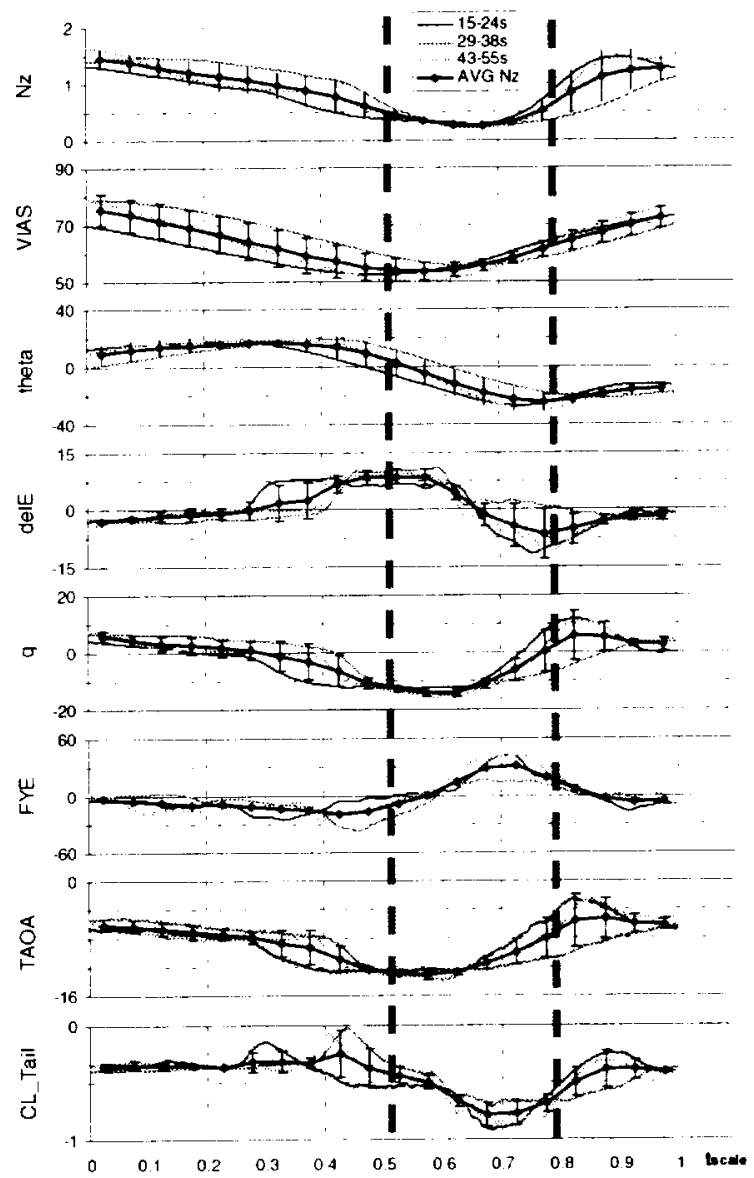

Figure 17. Three maneuvers (thin lines) and their average (thick line) vs. scaled time for Failed Boot, $\delta F=$ $20^{\circ}, V=50 \mathrm{kts}=1.0 \mathrm{Vs}$ test point. Error bars and $\bar{s}_{t u r}$ averaging region are indicated.

To isolate the target portion of the maneuver and eliminate the entry and exit variations. the values centered around the $N_{-\min }$ bin can be averaged. The quantity $\bar{s}_{t u r}$ is defined similarly to $\bar{s}$, but only averaged over the immediate target neighborhood. Let $k_{0}$ define the bin which contains $N_{--m i n}$, and $n$ define the number of hins in the neighborhood.

$$
\bar{s}_{t u r}=\frac{I}{n} \sum_{k=k_{11}-\frac{n}{2}}^{k_{11}+\frac{n}{2}} s(k)
$$

For the non-critical case in Figure $16, k_{0}=0.5, n=6$; for the critical case in Figure 17, $k_{0}=0.65, n=6$. These neighborhoods are shown in the figures with a thick dashed line. The ${ }^{-} s_{t u r}$ values are listed in Table 1. As can be seen from the figures and table, the pilot's ability to repeat the target portions of the maneuver were generally tighter for the non-critical case than the critical case. For both cases, the pilot's ability to achicve the $N$. 
was within about $\pm 0.1 \mathrm{G}$ precision. Around the target velocity, however, the tolerances for the critical case were actually better than for the non-critical case. For the overall velocity error, $\bar{s}$, on the other hand, the opposite was true. The pitch attitude seemed to be the most difficult target to achieve. The pitch repeatability for the critical case was more than double that of the non-critical case.

\begin{tabular}{|c|c|c|}
\hline Configuration: & RI & FB \\
Ice Shape, $\delta F$, & $0^{\circ}$ & $20^{\circ}$ \\
$V / \mathrm{Ns}$ & 1.5 & 1.0 \\
\hline$N z(\mathrm{G})$ & 0.12 & 0.08 \\
\hline$V I A S(\mathrm{kts})$ & 4.2 & 2.8 \\
\hline theta (deg) & 2.8 & 8.3 \\
\hline
\end{tabular}

Table 1. Repeatability analysis $-\bar{s}_{\text {tar }}$ precision levels within both a non-critical and critical configuration for the pushover maneuver.

With a bin average value established, the accuracy of achicving the targets may now be addressed. The accuracy shall be defined as the difference (Dif) between the average of the $k_{0}$ bin and the target quantity, $\mid \overline{\bar{Q}}\left(k_{0}\right)-Q_{\text {turget }}$. These values are presented in Table 2 . Again, the greatest difficulty occurred in meeting the pitch angle at the minimum $N_{z}$. Otherwise, these results suggest that the pilot should be able to achieve the targets to roughly the same degree of accuracy and precision regardless of the level of ice contamination.

\begin{tabular}{|c|c|c|c|}
\hline \multirow{2}{*}{$\begin{array}{c}\text { Configura- } \\
\text { tion: }\end{array}$} & \multicolumn{3}{|c|}{ RI, $\delta F=0^{\circ}, V=1.5 \mathrm{Vs}$} \\
\cline { 2 - 4 } & Actual & Target & Dif \\
\hline$N z(\mathrm{G})$ & 0.07 & 0 & 0.07 \\
\hline$V I A S$ (kts) & 108 & 100 & 8 \\
\hline theta (deg) & -6.5 & 3.3 & -9.8 \\
\hline
\end{tabular}

\begin{tabular}{|c|c|c|c|}
\hline \multirow{2}{*}{$\begin{array}{c}\text { Configura- } \\
\text { tion: }\end{array}$} & \multicolumn{3}{|c|}{$\mathrm{FB}, \delta F=20^{\circ}, V=1.0 \mathrm{Vs}$} \\
\cline { 2 - 4 } & Actual & Target & Dif \\
\hline$N_{z}(\mathrm{G})$ & 0.24 & 0.17 & 0.07 \\
\hline VIAS $(\mathrm{kts})$ & 55 & 55 & 0 \\
\hline theta (deg) & -14 & 1.8 & -15.8 \\
\hline
\end{tabular}

Table 2. Accuracy of achieving the target values for both non-critical and critical pushover cases.

\section{Conclusions}

A detailed study of two maneuvers, the pushover and elevator doublet, has been made. These maneuvers were performed during the NASA/FAA Tailplane Icing
Program, which was designed to better understand icecontaminated tailplane stall. This series of flight tests was flown in a modified DHC-6 Twin Otter with artificial ice shapes attached to the leading edge of the horizontal stabilizer.

The degradation of longitudinal stability and control was considered primarily through the control force criterion used for certification. The degradation due to increasing ice contamination severity and increasing flap deflection was documented. It was also found that the pitch rate response is another good indicator of the longitudinal stability and control degradation.

This research program also allowed for a repeatability analysis of the pushover maneuver. A method was developed to evaluate the precision and accuracy of one pilot's ability in one aircraft to achieve the required target parameters of $N_{z}, V$ and $\theta$. In addition to the numbers given in Tables 1 and 2, these results suggest that the level of ice contamination did not substantially affect the pilot's ability to achieve the target parameters.

\section{References}

1 Trunov, O.K. \& Ingleman-Sundberg, M., "On the Problem of Horizontal Tail Stall due to Ice: Aerodynamic Background and Comparison between Results from Wind Tunnel and Flight Tests", Swedish-Soviet Working Group on Scientific-Technical Cooperation in the Field of Flight Safety, JR-3, 1985.

${ }^{2}$ Ingleman-Sundberg, M. \& Trunov, O.K., "Wind Tunnel Investigation of the Hazardous Tail Stall due to Icing", Swedish-Soviet Working Group on ScientificTechnical Cooperation in the Field of Flight Safety, JR2. 1979.

${ }^{3}$ Ratvasky, T.J. \& Van Zante, J. Foss, "NASA/FAA Tailplane Icing Program Overview", AIAA 99-0370, 1999.

4 Ratvasky, T.J., Van Zante, J. Foss \& Sim, A.G., "NASA/FAA Tailplane Icing Program: Flight Test Report", to be published as a NASA TM, 1998.

Etkin, Bernard, Dynamics of Flight - Stability and control, John Wiley \& Sons, 2nd ed., 1982.

${ }^{6}$ ANM-100, Transport Airplane Directorate, Aircraft Certification Service, "Information: Recommended Method of Identification, Susceptibility to Ice Contaminated Tailplane Stall", FAA Memorandum, Apr. 29. 1994. 

Public reporting burden for this collection of information is estimated to average 1 hour per response, including the time for reviewing instructions, searching existing data sources, gathering and maintaining the data needed, and completing and reviewing the collection of information. Send comments regarding this burden estimate or any other aspect of this collection of information, including suggestions for reducing this burden, 10 Washington Headquarters Services, Directorate for Information Operations and Reports, 1215 Jefferson Davis Highway. Sulte 1204, Arlington. VA 22202-4302, and to the Office of Management and Budget. Paperwork Reduction Project (0704-0188), Washington, DC 20503.

\begin{tabular}{|l|c|c|}
\hline 1. AGENCY USE ONLY (Leave blank) & $\begin{array}{r}\text { 2. REPORT DATE } \\
\text { January } 1999\end{array}$ & $\begin{array}{r}\text { 3. REPOAT TYPE AND DATES COVERED } \\
\text { Technical Memorandum }\end{array}$ \\
\hline 4. TITLE AND SUBTITLE & $\begin{array}{r}\text { 5. FUNDING NUMBERS } \\
\hline\end{array}$
\end{tabular}

Investigation of Dynamic Flight Maneuvers With an Iced Tailplane

6. AUTHOR(S)

WU-548-20-23-00

Judith Foss Van Zante and Thomas P. Ratvasky

National Aeronautics and Space Administration

Lewis Research Center

Cleveland, Ohio 441.35-3191

8. PERFORMING ORGANIZATION

REPORT NUMBER

$E-11470$

\section{SPONSORING/MONITORING AGENCY NAME(S) AND ADDRESS(ES)}

National Aeronautics and Space Administration

Washington, DC 20546-0001

10. SPONSORING/MONITORING AGENCY REPORT NUMBER

NASA TM-1998-208849

AIAA-99-0371

\section{SUPPLEMENTARY NOTES}

Prepared for the 37th Aerospace Sciences Meeting \& Exhibit sponsored by the American Institute of Aeronautics and Astronautics, Reno, Nevada. January 11-14, 1999. Judith Foss Van Zante, Dynacs Engineering Co., Inc., 2001 Aerospace Parkway, Brook Park, Ohio 44142 (work funded by NASA Contract NAS3-9808) and Thomas P. Ratvasky, NASA Lewis Research Center. Responsible person, Judith Foss Van Zante, organization code 5840. (216) 433-3587.

12a. DISTRIBUTION/AVAILABILITY STATEMENT

Unclassified - Unlimited

Subject Categories: 03 and 08

\section{2b. DISTRIBUTION CODE}

This publication is available from the NASA Center for AeroSpace Information. (301) 621-0390.

13. ABSTRACT (Maximum 200 words)

A detailed analysis of two of the dynamic maneuvers, the pushover and elevator doublet, from the NASA/FÁ Tailplane Icing Program are discussed. For this series of flight tests, artificial ice shapes were attached to the leading edge of the horizontal stabilizer of the NASA Lewis Research Center icing aircraft, a DHC-6 Twin Otter. The purpose of these tests was to learn more about ice-contaminated tailplane stall (ICTS), the known cause of 16 accidents resulting in 139 fatalities. The pushover has been employed by the FAA, JAA and Transport Canada for tailplane icing certification. This research analyzes the pushover and reports on the maneuver performance degradation due to ice shape severity and flap deflection. A repeatability analysis suggests tolerances for meeting the required targets of the maneuver. A second maneuver, the elevator doublet, is also studied.

14. SUBJECT TERMS

Aircraft icing; Tailplane icing; Tailplane performance; Maneuver evaluation 15. NUMBER OF PAGES 16

\begin{tabular}{|c|c|}
\hline $\begin{array}{c}\text { 17. SECURITY CLASSIFICATION } \\
\text { OF REPORT } \\
\text { Unclassified }\end{array}$ & $\begin{array}{c}\text { 18. SECURITY CLASSIFICATION } \\
\text { OF THIS PAGE } \\
\text { Unclassified }\end{array}$ \\
\hline
\end{tabular}

19. SECURITY CLASSIFICATION OF ABSTRACT Unclassified
$A 03$

\section{LIMITATION OF ABSTRACT}

